\title{
Grazing on fleshy seaweeds by sea urchins facilitates sponge Cliona viridis growth
}

\author{
E. Cebrian*, M. J. Uriz \\ Centre d'Estudis Avançats de Blanes, CSIC, c/o Accés a la Cala St. Francesc 14, 17300 Blanes, Spain
}

\begin{abstract}
We studied possible interactions among invertebrate species and algal assemblages in a shallow sublittoral community of the Mediterranean Sea using a 2-step approach. First, we analysed the general pattern by correlation analysis. Thereafter, we experimentally assessed cause-effect relationships between the species or assemblages that were clearly related in the correlation study. The abundance of Cliona viridis (Schmidt 1862) was positively correlated with that of sea urchins and negatively correlated with fleshy algal cover. These relationships were confirmed by field experiments: treatments without fleshy algae, owing to both natural and simulated sea urchin grazing, promoted C. viridis growth significantly more than controls. Our results support the hypothesis that sea urchin grazing on seaweeds increases light availability at the basal stratum, which favours the primary production of the symbiotic zooxanthellae and thus $C$. viridis growth through nutrient transfer. We found a network of interactions with several signs, directions and strengths: a strong positive indirect interaction ('facilitation') between sea urchins and $C$. viridis, a negative direct interaction between sea urchins and seaweeds ('predation'), a negative direct interaction between seaweeds and $C$. viridis ('shading-interference') and a weaker but significant direct interaction between $C$. viridis and Pione vastifica ('space competition'). The multiple interactions observed suggest a cascade that involves 4 trophic levels: primary producers, herbivorous, carnivorous, and filterfeeders. This cascading process can have negative cryptic implications on the environment, as the excavating sponge $C$. viridis is a bio-eroder that may strongly impact the shallow sublittoral landscape by producing substrate weakening and instability. The knowledge acquired on the sign and strength of these multi-species interactions is useful to model and predict the responses of shallow benthic communities to anthropogenic disturbances (i.e. overfishing and eutrophication).
\end{abstract}

KEY WORDS: Excavating sponges · Facilitation $\cdot$ Indirect interactions $\cdot$ Bio-erosion $\cdot$ Mediterranean Sea

\section{INTRODUCTION}

Communities consist of many related species embedded in a web of interactions in such a way that a change in one species can affect a great number of others (Pennings 1997), sometimes producing drastic results through what is known in ecology as a cascading effect (e.g. Estes \& Duggins 1995). Therefore, knowledge of interspecies interactions is essential to gain an understanding of the structure patterns, as well as to predict changes, in natural communities.

Interspecies interactions have traditionally been classified into 'interference', the negative effect of one species on another (e.g. Steele 1998), and 'facilitation', the positive effect of one species on another (Callaway et al. 1991). Both can be divided into 'direct', when one species directly affects another, and 'indirect', when the effect of one species on another is mediated by an intermediate third species. The effects of indirect interactions on communities are much more difficult to assess than those of direct ones; therefore, the former have received less attention (Usio 2000). However, both types of interactions are important and can strongly affect species composition of the community (e.g. Dethier \& Duggins 1984).

Facilitation has proven to be relevant in marine ecosystem interactions (e.g. Bruno et al. 2003). Most of the studies on facilitation fit in the context of commu- 
nity succession (e.g. Benedetti-Cecchi 2000), food web and predator-prey interactions (e.g. Menge 2000) and dispersal facilitation (e.g Amsler et al. 1999), and have been mainly performed in tropical areas (e.g. Webster \& Almany 2002) or intertidal habitats (e.g. Dethier \& Duggins 1984, Menge 1995, Benedetti-Cecchi 2000). However, few studies have investigated the impact of facilitation, and more particularly of indirect facilitation, on sublittoral benthic communities of temperate ecosystems, and of those only one (Stachowicz \& Hay 1999) involved filter-feeding invertebrates.

Indirect facilitation is among the ecological processes that may drive a cascade of effects that will be more difficult to predict than one derived from direct interactions. Some examples of indirect facilitations that produce cascades in marine sublittoral ecosystems have become paradigmatic due to their unexpected impacts on benthic communities (e.g. Estes \& Duggins 1995). With regard to Mediterranean benthos, few instances of cascading effects have been documented up to now, and those that have refer to food-webs involving fish, sea urchin and seaweeds (e.g. Sala et al. 1998, Pinnegar et al. 2000).

Our goal was to study both direct and indirect interactions between the main species or species groups (sea urchins, seaweeds and excavating sponges) dominating a sublittoral benthic Mediterranean biotope. We aimed to take into account the most conspicuous interactions without a priori considering whether they were positive or negative, in order to observe their strength and direction as well as possible outcomes in the community. The interactions observed may represent an example of a cascade involving sponges, and add a further step to previously reported interactions among fish, sea urchins and seaweeds.

\section{MATERIALS AND METHODS}

We first studied possible relationships between sea urchins, fleshy seaweeds, and excavating sponges by correlation analysis. This enabled us to design a manipulative experiment to establish the cause-effect relationships between the species or groups of species that were clearly related in the correlation study.

Study site and community description. The correlation study and the manipulative experiment were conducted in a shallow rocky bottom of the infralittoral community of Blanes (NE Spain) $\left(41^{\circ} 40.4^{\prime} \mathrm{N}\right.$, $\left.2^{\circ} 48.2^{\prime} \mathrm{E}\right)$. The assemblage studied was established in a photophilic seaweed biocoenosis (between 4 and $6 \mathrm{~m}$ depth) with algae distributed in 3 strata: an encrusting stratum dominated by the encrusting calcareous algae Lithophyllum incrustans Phillippi; a bush-like stratum dominated by Phaeophyceae (Halopteris scoparia Lin- naeus (Sauvageau), Padina pavonica (Linnaeus) Thivy and Dictyota dichotoma Hudson (Lamouroux)); and an epiphyte stratum dominated by Corallina granifera Ellis \& Solander. In the present study, we regarded all fleshy seaweed species as a single entity, because all appeared to exert a similar shading effect on the basal stratum and all were Phaeophyceae, which have been reported to be consumed with similar preference by sea urchins (Verlaque 1987). Filter feeders such as the excavating sponges Cliona viridis (Schmidt, 1862) and Pione vastifica (Hancock, 1849) were also present and even abundant in the study zone. Other sessile macroinvertebrates were much less abundant. Paracentrotus lividus (Lamarck, 1816) was the most abundant echinoderm, but scattered individuals of Arbacia lixula (Linnaeus, 1758) were also detected.

Cliona viridis is the most common excavating sponge in the western Mediterranean (Rosell \& Uriz 1992). It is the only sponge in the study area that harbours symbiotic zooxanthellae, and the sponge-dinoflagellates symbiosis has been reported to be functional (Rosell \& Uriz 1992).

Pione vastifica is a reddish-to-orange excavating sponge without symbiotic zooxanthellae (but see a different species misnamed Pione vastifica that harbours zooxanthellae; Steindler et al. 2001). Several forms of $P$. vastifica have been recorded around the world (Rosell \& Uriz 2002), but this species is unlikely to be cosmopolitan given its oviparous reproduction and the short dispersion capabilities of the resulting creeping larvae (Mariani et al. 2000).

The sea urchin Paracentrotus lividus is found from the shallow sublittoral down to depths of $4 \mathrm{~m}$. It plays a key role in the control of shallow benthic communities through grazing on seaweeds (Verlaque 1987). Sometimes its populations experience rapid increases owing to reduction of its natural predators by overfishing (Sala et al. 1998). In extreme cases, the reduction in seaweed biomass due to expanding populations of $P$. lividus is so drastic that it leads to particular landscapes known as 'barrens' (Sala et al. 1998).

Correlation analysis. We placed a set of quadrats of $625 \mathrm{~cm}^{2}$ each $(\mathrm{N}=40)$ haphazardly in the study site. The number of sea urchins in these quadrats was counted. First, fleshy algae coverage was measured by means of $25 \times 25 \mathrm{~cm}$ reticulated quadrats, divided into 25 subquadrats of $5 \times 5 \mathrm{~cm}$ (Cebrian \& Ballesteros 2000). We recorded the number of subquadrats where algae were present and then removed fleshy algae to reveal the calcareous algae and excavating sponges. Cover of calcareous algae and excavating sponges was then quantified by outlining their area onto a plastic sheet.

Relationships between the coverage of fleshy seaweeds, calcareous algae, Cliona viridis and Pione vas- 
tifica, and the number of sea urchins were assessed by correlation analysis. Multiple regression analysis was not used because of the clear multi-colinearity of some independent variables such as number of sea urchins and coverage of fleshy algae (Berry \& Feldman 1985).

Experimental study. We conducted a manipulative field experiment to test the causality of the most relevant correlation relationships. The experiment was carried out over 8 mo (February to September 2002) in a set of quadrats $(\mathrm{N}=30)$ placed haphazardly in the same photophilic biocoenosis where the correlation study was conducted. In this experiment, quadrats of $300 \mathrm{~cm}^{2}$ each were used instead of those of $625 \mathrm{~cm}^{2}$ of the correlation study, because the former area had proven to be representative of the biocenosis studied and matched the area covered by photographs.

Of the 2 excavating sponges found underneath the fleshy algae in the study area, only Cliona viridis was considered in this experiment. Pione vastifica was not analysed because of the difficulties of measuring its small papillae in the standardized pictures.

To measure the initial coverage of Cliona viridis, we removed all erect algae present in the quadrats and then photographed the sponge area at the beginning of the experiment (February) and before the period of seaweed growth.

Three treatments of 10 quadrats each were performed. Treatment 1 consisted of quadrats that were untouched except for removal of sea urchins. Treatment 2 consisted of quadrats in which seaweeds were removed in order to simulate the maximum grazing effect by sea urchins ('barrens'). Treatment 3 consisted of adding 4 sea urchins to each quadrat in order to approach the natural sea urchin density in a barrens landscape. The latter treatment was located on a narrow rocky platform surrounded by sand in such a way that sea urchins could not escape far from the quadrats.

The experimental zone was visited weekly to check and maintain treatment conditions. Seaweeds were removed and sea urchins were added to the corresponding treatments when necessary. However, on no occasion were the quadrats completely devoid of sea urchins, and thus the barrens effect was maintained.

At the end of the experiment (8 mo later), we removed all fleshy seaweeds from the quadrats to photograph and properly quantify cover of the underlying sponge Cliona viridis. Photographs covering $300 \mathrm{~cm}^{2}$ each were taken with a Nikonos camera with a $35 \mathrm{~mm}$ objective plus a close-up lens. Slides were digitized with a Nikon LS-2000 Scanner, and the sponge area was calculated with the NIH image program for Macintosh. Because the sponge excavates into the substrate, only the aquiferous papillae were visible. Thus, we estimated sponge cover to be the area comprising all papillae (to the nearest $\mathrm{mm}$ ), because a good correlation between this area and sponge biomass was reported previously by Mariani et al. (2000). Growth was assessed from changes in sponge area over time (8 mo). Growth ratio (GR) over the whole period was computed by the formula $\mathrm{GR}=\left(A_{\mathrm{f}}-A_{\mathrm{i}}\right) / A_{\mathrm{i}}$, where $A_{\mathrm{f}}$ is final sponge area and $A_{\mathrm{i}}$ is initial sponge area (Turon et al. 1998).

Coverage and growth in treatments (fleshy untouched algae, artificial grazing, and natural grazing by sea urchins) were analyzed by multivariate analysis of variance (MANOVA) (Statistica V4.1). Tukey's test was used for post hoc comparisons.

\section{RESULTS}

\section{Correlation analysis}

We observed a significant negative correlation between sea urchin number and fleshy seaweeds cover $(\mathrm{r}=-0.737, \mathrm{p}<0.001)$ (Fig. 1A) and between fleshy seaweed and Cliona viridis cover $(\mathrm{r}=-0.325, \mathrm{p}<$ 0.001) (Fig. 1B). The correlation between $C$. viridis and Pione vastifica cover was also negative $(\mathrm{r}=-0.366, \mathrm{p}<$ 0.001) (Fig. 1C). Conversely, the number of sea urchins was positively related to the cover of $C$. viridis $(\mathrm{r}=$ 0.631, p < 0.001) (Fig. 1D).

The other 2 relationships were weak. Although significant, correlation between Pione vastifica and fleshy seaweeds $(r=-0.130, p<0.05)$ (Fig. 1E) and sea urchin number $(\mathrm{r}=0.164, \mathrm{p}<0.01)$ (Fig. 1F) explained a very low percentage of the variance and, consequently, were not considered for the experimental study. We did not find any relationship between calcareous algae and the other variables analysed.

\section{Experimental study}

At the beginning of the experiment (initial time), the cover of Cliona viridis sponges did not differ significantly among the 3 treatments ( $p>0.05$ ) (Fig. 2). The sponge cover (mean $\pm \mathrm{SE}$ ) ranged from $0.34 \pm 0.1 \mathrm{~cm}^{2}$ to $1.07 \pm 0.2 \mathrm{~cm}^{2}$. However, at the end of the experiment (8 mo later), the cover of $C$. viridis was significantly higher in the 2 treatments with a grazing effect $\left(1.29 \pm 0.3 \mathrm{~cm}^{2}\right.$ in quadrats with seaweeds artificially removed [Treatment 2] and $2.02 \pm 0.7 \mathrm{~cm}^{2}$ in quadrats with 4 sea urchins added [Treatment 3]) than in quadrats with an untouched seaweed population $\left(0.19 \pm 0.08 \mathrm{~cm}^{2}\right.$; Treatment 1) (Fig. 2).

GRs of Cliona viridis during the experiment were higher in the 2 grazing treatments (Treatments 2 and 3 ; $1.88 \pm 0.7 \mathrm{~cm}^{2}$ in quadrats with artificially removed sea- 

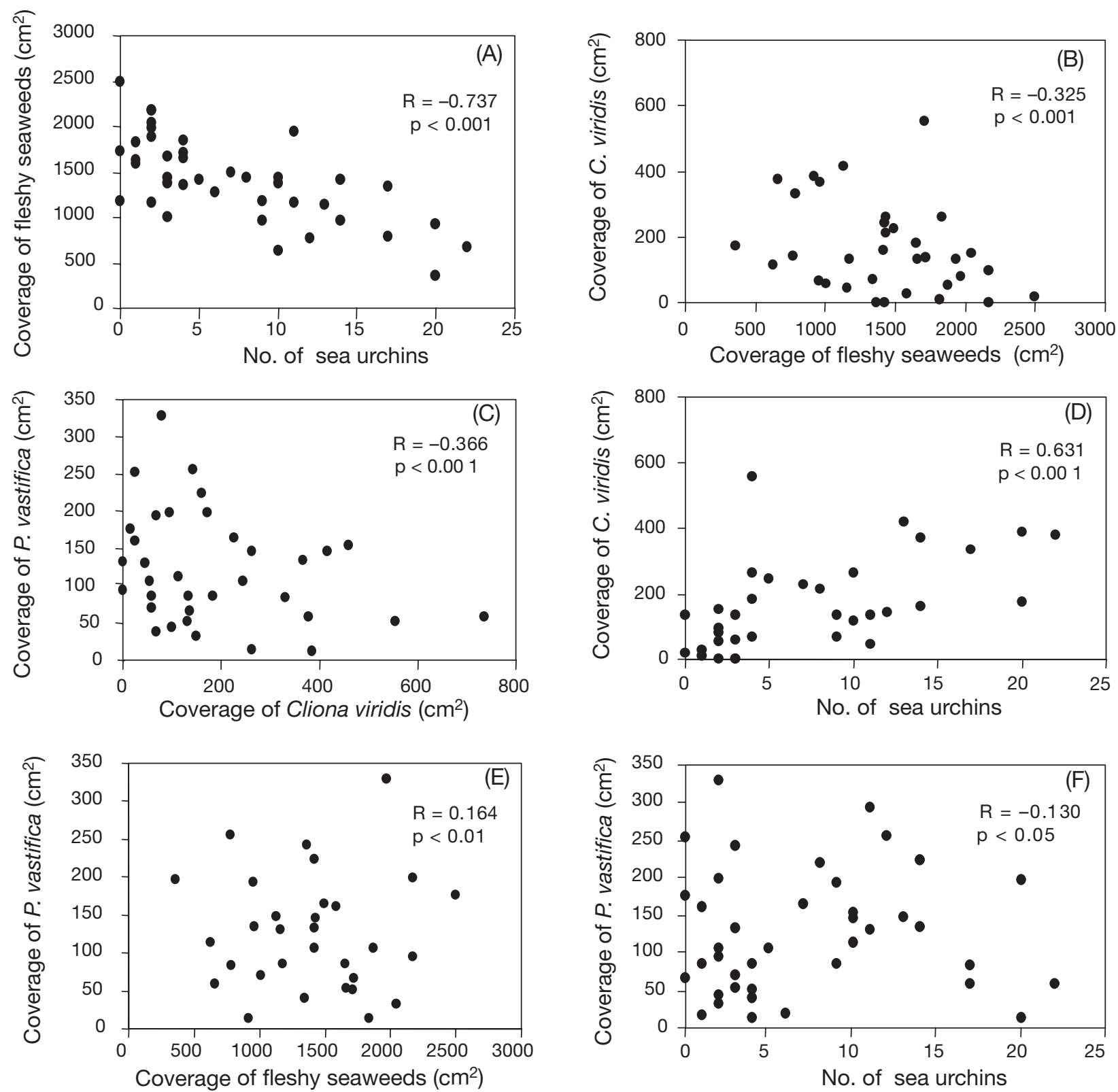

Fig. 1. Correlations between pairs of variables analysed

weeds and $1.40 \pm 0.6 \mathrm{~cm}^{2}$ in quadrats with sea urchins added) than in quadrats with untouched seaweeds $\left(-0.132 \pm 0.10 \mathrm{~cm}^{2}\right.$; Treatment 1$)(\mathrm{p}<0.05)$ (Fig. 3).

\section{DISCUSSION}

Interactions between seaweeds and grazers have been extensively studied (e.g. Pinnegar et al. 2000). In the sublittoral rocky habitats of the Mediterranean, it has been reported that these interactions strongly influence the succession and dynamics of algal communities in such a way that their outcomes largely determine algal assemblages (e.g. Verlaque 1987, Sala et al. 1998). Our study goes further and shows that grazing by sea urchins exerts an indirect effect on the growth of excavating sponges.

The abundance of Cliona viridis sponges was positively correlated with that of sea urchins and negatively correlated with fleshy seaweed cover. These correlations were confirmed by the field experiment, as treatments without seaweeds (owing to both natural and simulated sea urchin grazing) had significantly increased coverage of $C$. viridis relative to control areas. This experiment indicated that the greater growth of $C$. viridis was not due to the sea urchins 


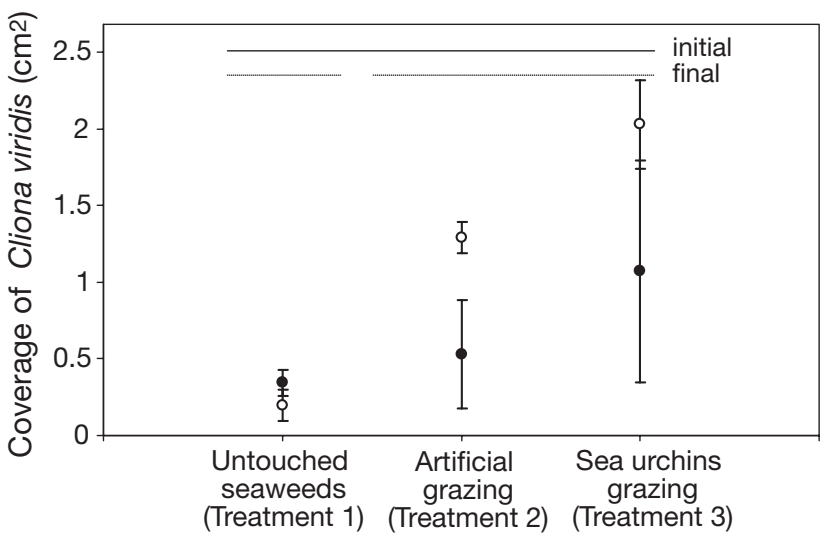

Fig. 2. Cliona viridis. Mean sponge cover of 3 treatments at beginning ( $\bullet$ : initial time) and end ( 0 : final time) of the field experiment. Vertical bars $=$ SE. Horizontal bars connect results which did not differ significantly (Tukey's test, $\mathrm{p}<0.05$ )

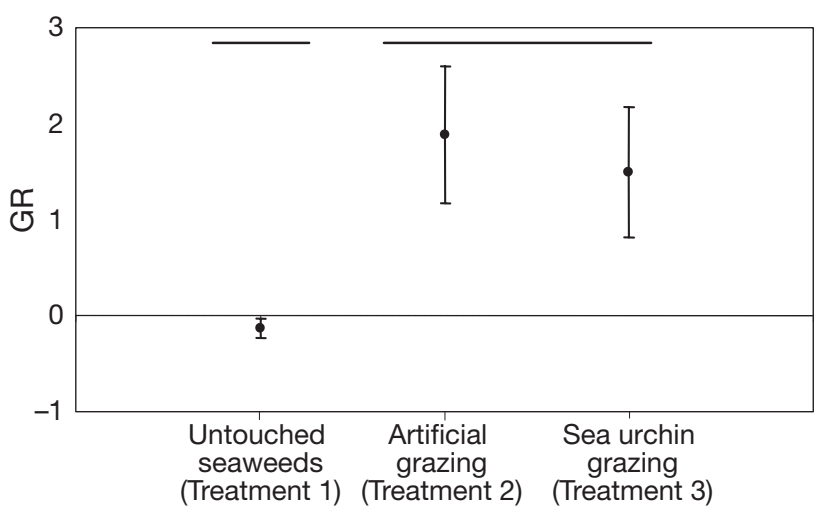

Fig. 3. Cliona viridis. Mean growth ratios (GR; see 'Materials and methods') in 3 experimental treatments over 8 mo. Error bars: \pm SE. Horizontal bars connect results which did not differ significantly (Tukey's test, $\mathrm{p}<0.05$ )

themselves but to the absence of fleshy seaweeds. GRs of $C$. viridis sponges in quadrats with natural seaweed cover were strongly negative during the field experiment. This was unexpected, because it has been reported that most temperate sponges grow mainly from early spring to summer as a function of temperature (Turon et al. 1998). However, Rosell \& Uriz (1992) found that temperature increased GRs of $C$. viridis only in lighted habitats. Their results suggest that light has a greater influence on the growth of this sponge than temperature by affecting the production (photosynthesis) of its symbiotic zooxanthellae. This may explain why the GRs of $C$. viridis in the quadrats covered by fleshy algae were negative, since the experiment was conducted during the period of maximum seaweed development and shading. In comparison, our results support the hypothesis that sea urchin grazing on seaweeds increases light availability at the basal stratum, which favours the primary production of symbiotic zooxanthellae (Rosell \& Uriz 1992) and may therefore enhance $C$. viridis growth through nutrient transfer.

Although weak, the negative correlation between Cliona viridis and Pione vastifica may signal a competitive relationship between both excavating sponges for the available calcareous substrate. These sponges bore into calcium carbonate substrates (Rosell \& Uriz 2002), which in the study area are restricted to thin, incrusting calcareous algae that almost completely cover the rocky substrate. As for their respective boring capacity, $C$. viridis is much more aggressive than $P$. vastifica (Rosell \& Uriz 2002). In this regard, the inhibition of $C$. viridis growth by fleshy algae shading may have an indirect positive effect on $P$. vastifica growth. Sea urchin grazing on fleshy seaweeds might thus have an indirect and negative effect on $P$. vastifica by facilitating the growth of its direct competitor, $C$. viridis. However, the small size of the $P$. Vastifica papillae prevented its adequate quantification in the pictures used for monitoring sponge growth in our experimental study. Further experimental research at an adequate scale should be conducted in order to ascertain the interactions that were not tested experimentally in this study.

This simple study indicated the existence of a network of interactions (Fig. 4) with several signs, directions and strengths: positive indirect interactions (facilitation) between sea urchins and Cliona viridis and (although weaker) between fleshy seaweeds and Pione vastifica; and negative direct interactions between sea urchins and seaweeds (grazing), between seaweeds and $C$. viridis (interference by shading), and possibly between $C$. viridis and $P$. vastifica (space competition). This network of interactions can be tackled only by studies that bring together the main species or functional groups of species of the community, rather than by studies that focus solely on trophic or competitive interactions between pairs of species.

The multiple interactions observed in this study suggest a cascade event (sensu Menge 1995) that involves 4 trophic levels: primary producers, herbivorous, carnivorous, and filter-feeders. Overfishing along Mediterranean shores has reduced the abundance of sea urchin predators (fish) in some areas, which in turn has increased sea urchin populations (e.g. Sala et al. 1998). These populations have removed all erect algae (Verlaque 1987, Sala et al. 1998) leading to the formation of typical barren areas dominated by crustose calcareous algae. Furthermore, as shown in our study, sea urchin grazing results in the proliferation of the excavating sponge Cliona viridis. Predation, grazing, competition, interference and facilitation may be involved in this sublittoral network. Therefore, sea urchin proliferation may increase $C$. viridis populations in shallow waters, which enhances bio-erosion. Although some positive 


\section{OVERFISHING}

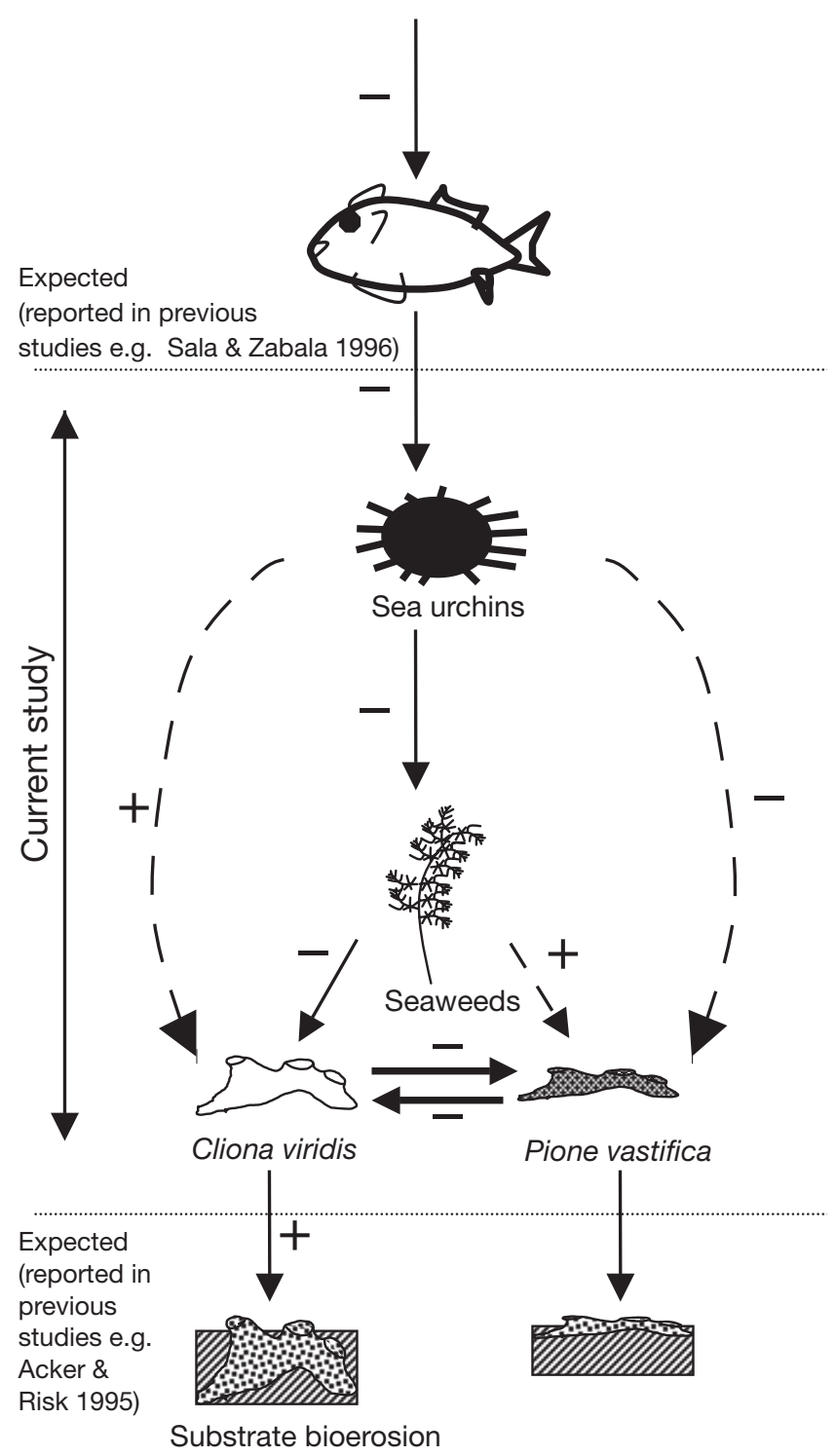

Fig. 4. Network of interactions expected in a shallow rocky ecosystem in the Mediterranean. Solid lines = direct interactions; broken lines $=$ indirect interactions

effects of bio-erosion could be envisaged, via the generation of new microhabitats that may favour the presence of further species, the main expected consequences are negative. Although not yet quantified in the Mediterranean, the magnitude of bio-erosion by sponges appears at first sight to be significant (unpubl.). Excavating sponges were reported to erode as much as 8 to $24 \mathrm{~kg}$ of calcareous substrate $\mathrm{m}^{-2} \mathrm{yr}^{-1}$ in tropical areas (Acker \& Risk 1985); thus, a negative impact in the Mediterranean shallow sublittoral landscape by substrate weakening and instability may also be expected.
Cryptic interactions may have strong effects in a local context, particularly if convergent conditions occur (Menge 2000). The strength of the interactions studied can be enhanced and the resulting effects magnified by increasing eutrophication of the littoral, since eutrophy also enhances Cliona viridis growth (Muricy 1991).

Knowledge on the sign and strength of multi-species interactions is necessary for any attempt to model and predict the responses of benthic communities to anthropogenic disturbances (e.g. overfishing and contamination), which is indispensable for management decisions.

Acknowledgements. We thank R. Martí, S. de Caralt and J. Corona for their help with fieldwork. This research was partially funded by grants from the European Community (SPONGES project COOP-CT-205-017800) and the CICYT (Spain) (INTERGEN, CTM2004-05265-CO2/MAR) to M.J.U.

\section{LITERATURE CITED}

Acker KL, Risk MJ (1985) Substrate destruction and sediment production by boring sponge Cliona caribbea on Grand Cayman Island. J Sediment Petrol 55:705-711

Amsler CD, McClintock JB, Baker BJ (1999) Antarctic feeding triangle: defensive interactions between macroalgae, sea urchins, and sea anemones. Mar Ecol Prog Ser 183: 105-114

Benedetti-Cecchi L (2000) Predicting direct and indirect interactions during succession in a mid-littoral rocky shore assemblage. Ecol Monogr 70:45-72

Berry WD, Feldman S (1985) Multiple regression in practice. Quantitative applications in the social sciences. Sage, London

Bruno JB, Stachowicz JJ, Bertness MD (2003) Inclusion of facilitation into ecological theory. Trends Ecol Evol 18(3): $119-125$

Callaway R, Nadkarni NM, Mahal BE (1991) Facilitation and interference of Quercus douglasii on understory productivity in central California. Ecology 72:1484-1499

Cebrian E, Ballesteros E (2000) Shallow rocky bottom benthic assemblages as calcium carbonate producers in the Alboran Sea (southwestern Mediterranean). Oceanol Acta 23: 311-322

Dethier MN, Duggins DO (1984) An 'indirect commensalism' between marine herbivores and the importance of competitive hierarchies. Am Nat 124:205-219

Estes JA, Duggins DO (1995) Sea otters and kelp forests in Alaska: generality and variation in a community ecological paradigm. Ecol Monogr 65:75-100

Mariani S, Uriz MJ, Turon X (2000) Larval bloom of the oviparous sponge Cliona viridis: coupling of larval abundance and adult distribution. Mar Biol 137:783-790

Menge BA (1995) Indirect effects in marine rocky intertidal interaction webs: patterns and importance. Ecol Monogr 65:21-74

Menge BA (2000) Top-down and bottom-up community regulation in marine rocky intertidal habitats. J Exp Mar Biol Ecol 250:257-289

Muricy G (1991) Structure des peuplements de spongiaires 
autour de l'égout de Cartiou (Marseille, France). Vie Milieu 41:205-221

Pennings SC (1997) Indirect interactions on coral reefs. In: Birkeland C (ed) Life and death of coral reefs. Chapman \& Hall, New York

Pinnegar JK, Polunin NVC, Francour P, Badalamenti F and 7 others (2000) Trophic cascades in benthic marine ecosystems: lessons for fisheries and protected-area management. Environ Conserv 27:179-200

Rosell D, Uriz MJ (1992) Do associated zooxanthellae and the nature of the substratum affect survival, attachment and growth of Cliona viridis (Porifera: Hadromerida)? An experimental approach. Mar Biol 114:503-507

Rosell D, Uriz MJ (2002) Excavating and endolithic sponges species (Porifera) from the Mediterranean: species description and identification key. Org Divers Evol 2:55-86

Sala E, Zabala M (1996) Fish predation and the structure of the sea urchin Paracentrotus lividus populations in the NW Mediterranean. Mar Ecol Prog Ser 140:71-81

Sala E, Bouderesque CF, Harmelin-Vivien M (1998) Fishing trophic cascades, and the structure of algal assemblages: evaluation of an old but interesting paradigm. Oikos 82: 425-439

Editorial responsibility: Otto Kinne (Editor-in-Chief), Oldendorf/Luhe, Germany
Stachowicz JJ, Hay ME (1999) Reducing predation through chemically mediated camouflage: indirect effects of plant defenses on herbivores. Ecology 80:495-509

Steele MA (1998) The relative importance of predation and competition in two reef fishes. Oecologia 115:222-232

Steindler L, Beer S, Peretzman-Shemer A, Nyberg C, Ilan M (2001) Photoadaptation of zooxanthellae in the sponge Cliona vastifica from the Red Sea, as measured in situ. Mar Biol 138:511-515

Turon X, Tarjuelo I, Uriz MJ (1998) Growth dynamics and mortality of the encrusting sponge Crambe crambe (Poecilosclerida) in contrasting habitats: correlation with population structure and investment in defence. Funct Ecol 12: $631-639$

Usio N (2000) Effects of crayfish on leaf processing and invertebrate colonisation of leaves in a headwater stream: decoupling of trophic cascade. Oecologia 128:608-614

Verlaque M (1987) Relations entre Paracentrotus lividus (Lamarck) et le phytobenthos de Méditerranée occidentale. PhD thesis, Université d'Aix-Marseille II

Webster MS, Almany GR (2002) Positive indirect effects in a coral reef fish community. Ecol Lett 5:549-557

Submitted: January 19, 2006; Accepted: March 22, 2006

Proofs received from author(s): September 27, 2006 